\title{
Tissue plasminogen activator in the treatment of superior vena caval thrombosis associated with parenteral nutrition
}

\author{
G.R. Barclay, K. Allen and C.R. Pennington \\ Department of Medicine, Ninewells Hospital and Medical School, Dundee DD1 9SY, UK.
}

\begin{abstract}
Summary: Two patients, one of whom was pregnant, developed superior vena caval thrombosis while receiving central parenteral nutrition. They were successfully treated with recombinant tissue plasminogen activator (t-PA).
\end{abstract}

\section{Introduction}

Superior vena caval thrombosis (SVCT) is an uncommon but serious complication of parenteral nutrition with silicone catheters, occurring in $0.2-20 \%$ of patients. ${ }^{1-3}$ Factors known to predispose to the development of SVCT include the composition or incorrect positioning of the catheter and feeding solutions with a high osmolality, especially those in which all the non-protein energy is provided as dextrose. ${ }^{1}$ It has been successfully treated with streptokinase but the risk of haemorrhage and anaphylaxis limit the use of this drug. Recombinant tissue plasminogen (t-PA) activator is an effective fibrinolytic with a lower incidence of such adverse effects. To our knowledge it has not been described in the management of SVCT. This report outlines the use of t-PA in two patients who developed this complication while receiving $P N$.

\section{Case reports}

Case 1

An 80 year old man with small intestinal infarction necessitating the resection of all his jejunum and ileum was commenced on total parenteral nutrition. The nutrient solution is shown in Table I. Five months later he developed swelling of his face and arms typical of SVCT. He received intravenous streptokinase over 48 hours with clinical resolution and on the following day bilateral upper limb venography demonstrated clear veins. Parenteral nutrition was recommenced after 5 days but on the next day a further SVCT occurred which was confirmed by venography (Figure 1). A continuous

Correspondence: C.R. Pennington, B.Sc., M.D., F.R.C.P. (Ed.).

Accepted: 19 October 1989
Table I Parenteral nutrition solutions

\begin{tabular}{lcc}
\hline & \multicolumn{2}{c}{ Patient } \\
\hline Total volume & $l$ & 2 \\
Non-nitrogen energy & $2500 \mathrm{ml}$ & $2500 \mathrm{ml}$ \\
Dextrose & $1800 \mathrm{kcal}$ & $2400 \mathrm{kcal}$ \\
Fat emulsion - $20 \%$ & $450 \mathrm{~g}$ & $350 \mathrm{~g}$ \\
Amino-acid nitrogen & $*$ & $500 \mathrm{ml}$ \\
& $9 \mathrm{~g}$ & $11.5 \mathrm{~g}$ \\
\hline
\end{tabular}

Note: 1. Both patients received their calculated requirements of electrolytes, trace elements and vitamins. 2. Nutrient solutions were compounded in standard bags. 3. Patient 1 received two lipid containing bags each week. 4. Patient 2 received additional calcium and magnesium in an additional $100 \mathrm{ml}$ saline bag because of concern about lipid stability.

infusion of t-PA was commenced at $2 \mathrm{mg} /$ hour for 48 hours with careful monitoring of the thrombin time and fibrinogen degradation products. There was clinical resolution within 24 hours and subsequent venography demonstrated complete clearing of the thrombosis (Figure 2). Parenteral nutrition was restarted but the following day SVCT recurred. A second course of t-PA was effective and caused no complications.

Subsequent investigations demonstrated markedly abnormal platelet function with enhanced aggregation. He was commenced on stanozolol and subcutaneous heparin and parenteral nutrition was restarted. Two weeks later he developed recurrent intestinal infarction from which he died.

\section{Case 2}

A 38 year old pregnant woman was referred at 32 weeks gestation for nutritional support on account of subacute intestinal obstruction which first developed earlier in the pregnancy. In the absence of other abnormalities this was considered to reflect 


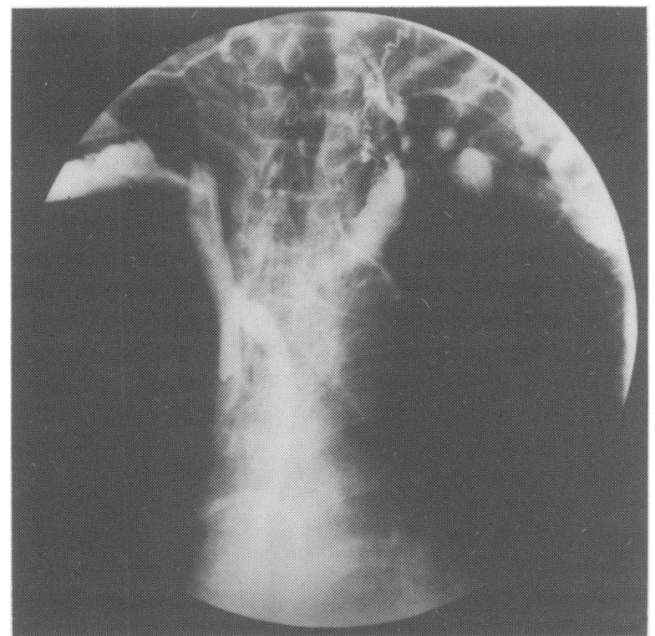

Figure 1 Case 1. A bilateral upper limb venogram showing occlusion of the superior vena cava with thrombus and retrograde blood flow through the azygos vein and collaterals.

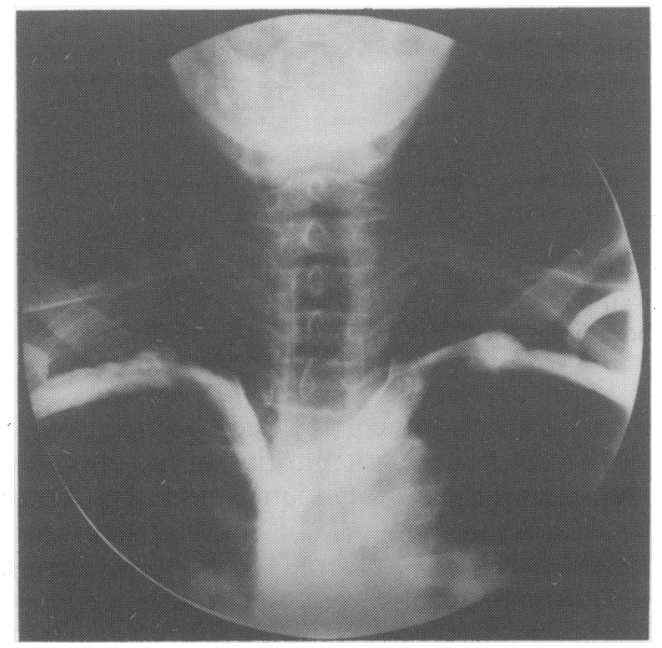

Figure 2 Case 1. A repeat venogram which demonstrates free flow in the superior vena cava with clearance of the thrombus.

adhesions following previous surgery for perforated appendicitis and infertility due to pelvic inflammatory disease, but investigation was precluded by the pregnancy. Total parenteral nutrition was commenced to facilitate fetal development prior to delivery and subsequent laparotomy. The nutrient regime is given in the Table I. Five days after starting treatment the patient developed swelling of her face and arms and a diagnosis of central vein thrombosis was confirmed by venography. Tissue plasminogen activator was infused via a peripheral vein at the rate of $2 \mathrm{mg} /$ hour for 48 hours under haematological control as in case 1. Within 24 hours there was clinical resolution and repeat venography demonstrated re-canalization of the SVCT. During the t-PA infusion there was no evidence of placental bleeding. Subsequently, a heparin infusion was commenced, two days later labour was induced and a healthy but premature baby delivered. Thereafter the cannula was removed. Laparotomy revealed a stenosing carcinoma of the ascending colon with peritoneal metastases.

\section{Discussion}

The development of SVCT is a life-threatening complication, particularly in those patients who are dependent upon parenteral nutrition, which requires rapid effective and safe treatment

Streptokinase can recanalise the $\mathrm{SVC}^{4}$ but it has certain disadvantages. Repeat usage within three months is contraindicated because of the risk of anaphylaxis. ${ }^{5}$ It also has the potential for causing serious haemorrhage as it activates the fibrinolytic system throughout the circulation and not just at the site of the thrombus. This is also of importance during pregnancy because bleeding and premature separation of the placenta could occur.

In contrast, t-PA has several advantages as it is the naturally occurring physiological agent that initiates fibrinolysis. Pharmacological preparations are produced by recombinant techniques and therefore anaphylaxis or the production of neutralizing antibodies is unlikely, making repeat usage after recent administration safe and effective. In theory there should be a low risk of serious bleeding because of the relative selectivity of t-PA for fibrin, and indeed at comparable thrombolytic doses it results in less degradation of fibrinogen than streptokinase. ${ }^{6}$ However, some clinical trials have reported a similar incidence of significant haemorrhage of around $15 \%$ although this was with a larger dose of t-PA $(150 \mathrm{mg})$ which has been shown to cause systemic activation of plasmin. ${ }^{7}$ In addition $80 \%$ of the significant bleeding events were associated with coronary bypass surgery or invasive vascular procedures. As both our patients received only $100 \mathrm{mg}$ of t-PA and no invasive procedures were planned the risk of bleeding was considered to be small and justifiable. Furthermore, single chain t-PA has a very short plasma half-life of 5 minutes ${ }^{7}$ so that if bleeding does occur or if urgent surgical or obstetric intervention is needed then normal haemostasis can rapidly be restored.

The safety of t-PA and streptokinase in human pregnancy has not been established. Neither agent crosses the placenta when administered to pregnant animals but both agents have resulted in fetal death 
from bleeding or separation of the placenta. However, we considered the short plasma half-life and relative clot selectivity of t-PA to be advantageous.

Neither of our patients suffered any definite side effects although increased platelet aggregation, which has been reported following t-PA, may have contributed to the repeated thrombosis in the first patient. ${ }^{7}$ It is possible though that this was unrelated as the patient developed recurrent SVCT after streptokinase even before t-PA was given. Furthermore, enhanced platelet aggregation occurs transiently soon after administration of

\section{References}

1. Pithie, A.D. \& Pennington, C.R. The incidence and management of central vein thrombosis during parenteral nutrition. Clin Nutr 1987, 6: 151-153.

2. Ladefoged, K., Efsen, F., Krogh Christoffersen, J. \& Jarnum, S. Long-term parenteral nutrition 11. Catheter-related complications. Scand J Gastroenterol 1981, 16: 913-919.

3. Bozzetti, F., Scarpa, D., Terno, G. et al. Subclavian venous thrombosis due to indwelling catheters: A prospective study in 52 patients. JPEN J Parenter Enteral Nutr 1983, 7: 560-562.

4. Halevy, A., Leonov, Y., Lewinshon, G., Witz, E. \& Orda, R. Thrombosis of superior vena cava during total parenteral nutrition managed successfully with low dose streptokinase. Intensive Care Med 1988, 14: 72-73.
t-PA whereas attenuation of platelet aggregation is a more characteristic late phenomenon. ${ }^{\text {? }}$

In conclusion we report the successful use of t-PA in two patients with SVCT and its potential advantages are discussed.

\section{Acknowledgements}

The authors wish to express their gratitude for helpful advice to Dr Jill Belch and Dr Alastair Todd, and to Dr David Taylor for permission to report the second case.

5. Prasad, A.B. (ed.). British National Formulary. British Medical Association, London, 1989 number 17: pp. 31 \& 112.

6. Runge, M.S., Quertermous, T. \& Haber, E. Plasminogen activators. Circulation 1989, 79: 217-224.

7. Loscalzo, J. \& Braunwald, E. Tissue plasminogen activator. $N$ Engl J Med 1988, 319: 925-931. 